\title{
PERANCANGAN ALAT MONITORING ARUS PADA CIRCUIT BREAKER DENGAN MENGGUNAKAN SENSOR ACS712 DAN TAMPILAN LCD
}

\author{
Rahmad Kurniawan \\ Sekolah Tinggi Manajemen Informatika Dan Komputer (STMIK DUMAI) \\ Jl. Utama Karya Bukit Batrem, Kota Dumai - Riau \\ E-mail : $\underline{\text { rahmad0412@gmail.com }}$
}

\begin{abstract}
ABSTRAK
Penelitian dilakukan dimana permasalahan adalah tidak dapat memonitoring arus listrik secara langsung, pengukuran masih menggunakan alat ukur Ampermeter dan membutuhkan seorang teknisi untuk bisa mengukur arus litrik tersebut. Perancangan alat ini menggunakan sensor ACS 712 sebagai sensor pendeteksi arus dan bahasa pemograman yang digunakan yaitu bahasa pemograman arduino $(\mathrm{Cl} \mathrm{C}++)$ sebagai bahasa pemograman mikrokontrollernya, dimana alat ini dapat mempermudah teknisi dalam melakukan perbaikan, dan dapat memonitoring arus menggunakan tampilan lcd secara langsung, kemudian dapat meminimalisir kecelakaan kerja pada teknisi.
\end{abstract}

Kata Kunci : Alat monitoring arus, sensor ACS 712, LCD

\section{PENDAhUluAN}

Circuit Breaker atau Pemutus Tegangan (PMT) adalah peralatan pada sistem tenaga listrik yang berfungsi untuk memutuskan atau menghubungkan pada rangkaian sistem tenaga listrik dan sisi beban yang dapat bekerja secara otomatis ketika terjadi gangguan atau secara manual ketika dilakukan perawatan atau perbaikan. Ketika kontak PMT dipisahkan, beda potensial di antara kontak tersebut menimbulkan medan elektrik di antara kontak tersebut.

Medan elektrik ini akan menimbulkan ionisasi yang mengakibatkan terjadinya perpindahan elektron bebas ke sisi beban sehingga muatan akan terus berpindah ke sisi beban dan arus tetap mengalir. Karena hal ini menimbulkan emisi thermis yang cukup besar, maka timbul busur api (arc) di antara kontak $P M T$ tersebut. Agar tidak mengganggu kestabilan sistem, maka arc tersebut harus segera dipadamkan.
Pada saat ini kita belum dapat mengetahui berapa kuat arus (A) yang ada pada Circuit Breaker, dan memonitoring langsung kestabilan arus yang pada Circuit Breaker tesebut kecuali mempunyai alat ukur khusus yaitu Ampermeter. Dengan mengukurnya secara manual, oleh karena itu perlu adanya alat monitoring arus listrik pada Circuit Breaker untuk dapat mengetahui berapa arus listrik yang pada menggalir Circuit Breaker tersebut.

Sistem proteksi tenaga listrik pada umumnya terdiri dari beberapa komponen yang di rancang untuk mengidentifikasi kondisi sistem tenaga listrik dan bekerja berdasarkan informasi yang diperoleh dari sistem tersebut seperti arus, tegangan atau sudut fasa antara keduanya. Informasi yang diperoleh dari sistem tenaga listrik akan digunakan untuk membandingkan besarannya dengan besaran ambang-batas (threshold setting) pada peralatan proteksi. 
INF ORMA T I K A

Jurnal Informatika, Manajemen dan Komputer, Vol. 10 No. 1, Mei 2018

eISSN : 2580-3042

pISSN : 1979-0694

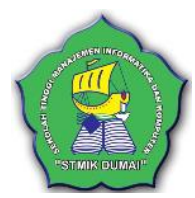

Apabila besaran yang diperoleh dari sistem melebihi setting ambang batas peralatan proteksi, maka sistem proteksi akan bekerja untuk mengamankan kondisi tersebut. Peralatan proteksi pada umumnya terdiri dari beberapa elemen yang dirancang untuk mengamati kondisi sistem dan melakukan suatu tindakan berdasarkan kondisi system. (Leoborus N. Hurtalu, 2016: hal.38).

Listrik memegang peranan yang vital dalam kehidupan. Dapat dikatakan bahwa listrik telah menjadi sumber energy utama dalam setiap kegiatan baik di rumah tangga maupun industri. Mulai dari peralatan dapur hingga mesin pabrik-pabrik besar bahkan pesawat terbang dan kapal laut, semua memerlukan listrik.

Sumber listrik PLN merupakan sumber energi listrik dengan arus bolak balik atau Alternating Current (AC) yang dihasilkan dari generator AC pembangkit listrik baik itu pembangkit listrik bertenaga disel (PLTD), pembangkit listrik bertenaga air (PLTA) ataupun pembangkit listrik lainnya yang menghasilkan sumber listrik dengan arus bolak-balik. (Andreas Alberth Mengko, 2016: hal.67-68).

Mikrokontroller menurut Muhammad Syahwil, 2013:hal.53 adalah sebuah sistem komputer fungsional dalam sebuah chip. Didalamnya terkandung sebuah inti prosesor, memori (sejumlah kecil RAM, memori program, atau keduanya), dan perlengkapan input-output. Mikrokontroler adalah salah satu dari bagian dasar dari suatu sistem komputer. Meskipun mempunyai bentuk yang jauh lebih kecil dari suatu komputer pribadi dan komputer mainframe, mikrokontroler dibagun dari elemen-elemen dasar yang sama. Secara sederhana, komputer dan menghasilkan output yang spesifik berdasarkan inputan yang diterima dan program yang di kerjakan.

Arduino adalah kit elektronik atau papan rangkaian elektronik open souce yang didalamnya terdapat komponen utama, yaitu sebuah chip mikrokontroler dengan jenis AVR dari perusahaan Atmel. Mikrokontroler itu sendiri adalah chip atau IC (integrated circuit) yang bisa di program dengan komputer tujuan menanamkan program pada mikrokontroler adalah agar rangkaian elektronik dapat membaca input, memproses input tersebut dan kemudian menghasilkan output sesuai yang diinginkan (Muhammad syahwil, 2013: hal.60).

Secara umum, Arduino terdiri dari dua bagian,yaitu:

1. Hardware berupa papan output/output (I/O) yang open Source.

2. Software arduino yang juga open source, meliputi software arduino IDE untuk menulis program dan driver untuk koneksi dengan komputer.

Tegangan atau seringkali orang menyebut dengan beda potensial (voltage) adalah kerja yang dilakukan untuk menggerakkan satu muatan (sebesar satu coulomb) pada elemen atau komponen dari satu terminal atau kutub keterminal atau kutub lainnya, atau pada kedua terminal atau kutub akan mempunyai beda potensial jika kita menggerakkan atau memindahkan muatan sebesar satu coulomb dari satu terminal ke terminal lainnya. Keterkaitan antara kerja yang dilakukan sebenarnya adalah energi yang dikeluarkan, sehingga pengertian diatas dapat disederhanakan bahwa tegangan adalah energi per satuan muatan. Secara matematis (Irwan Dinata dan Wahri Sunanda, 2015,hal:84).

Circuit breaker adalah peralatan sistem tenaga yang berfungsi untuk memutuskan hubungan antara sisi sumber tenaga listrik dan sisi beban yang dapat bekerja secara otomatis ketika terjadi gangguan atau secara manual ketika dilakukan perawatan atau perbaikan.

Ketika kontak dipisahkan, beda potensial di antara kontak tersebut menimbulkan medan elektrik di antara kontak tersebut. Medan elektrik ini akan menimbulkan ionisasi yang mengakibatkan terjadinya perpindahan electron bebas ke sisi beban sehingga muatan akan terus berpindah ke sisi beban dan arus tetap mengalir. Karena hal ini menimbulkan emisi termis yang cukup besar, maka timbul busur api (arc) di antara kontak PMT tersebut. Agar tidak mengganggu kestabilan sistem, maka arc tersebut harus segera dipadamkan (Leoborus N. Hurlatu, 2016,hal: 38) 
INF ORMA T I K A

Jurnal Informatika, Manajemen dan Komputer, Vol. 10 No. 1, Mei 2018

eISSN : 2580-3042

pISSN : 1979-0694

Kegunaan $L C D$ banyak sekali dalam perancangan suatu sistem dengan menggunakan menggunakan mikrokontroler, $L C D$ dapat berfungsi untuk menampilkan suatu nilai hasil sensor, menampilkan teks, atau menampilkan menu pada aplikasi mikrokontroler. Modul LCD matrix tersedia dengan konfigurasi 16 karakter dan 2 baris dengan setiap karakternya dibentuk oleh baris pixel. Adapun fitur yang disajikan dalam $L C D$ ini adalah: (Irwandinata,wahri sunanda,2015:hal.86).

Sensor analog arus ACS 712 seperti yang ditunjukkan pada Gambar 4. telah luas digunakan dalam dunia industry dan comercial untuk mendeteksi keberadaan arus $A C$ atau $D C$ yang mengalir pada sistem. Perangkat ini dilengkapi dengan rangkaian presisi pembacaan arus dan rangkaian efek linear Hall dengan kondutor tembaga yang diletakkan dekat bagian permukaan nonkonduksi.

Dengan mengalirnya arus pada konduktor tembaga akan dibangkitkan suatu medan magnet pada rangkaian Hall yang di konversi menjadi tegangan yang proporsional.

Resistansi internal bagian konduktif perangkat ini adalah $1,2 \mathrm{~m} \Omega$ sehingga rugirugi yang ditimbulkan menjadi lebih rendah dan dengan didesainya konduktor tembaga setipis mungkin maka bagian perangkat ini mampu menahan arus lebih (overcurrent) hingga 5x dari rating kemampuannya sehingga dalam aplikasinya tidak memerlukan optoisolator untuk mencegah perangkat terisolasi dari bagian nilai arus yang lebih tinggi (Syukriyadin, 2015,hal:115).

\section{METODE PENELITIAN}

Kerangka penelitian yang di gunakan dalam penelitian ini adalah sebagai berikut :

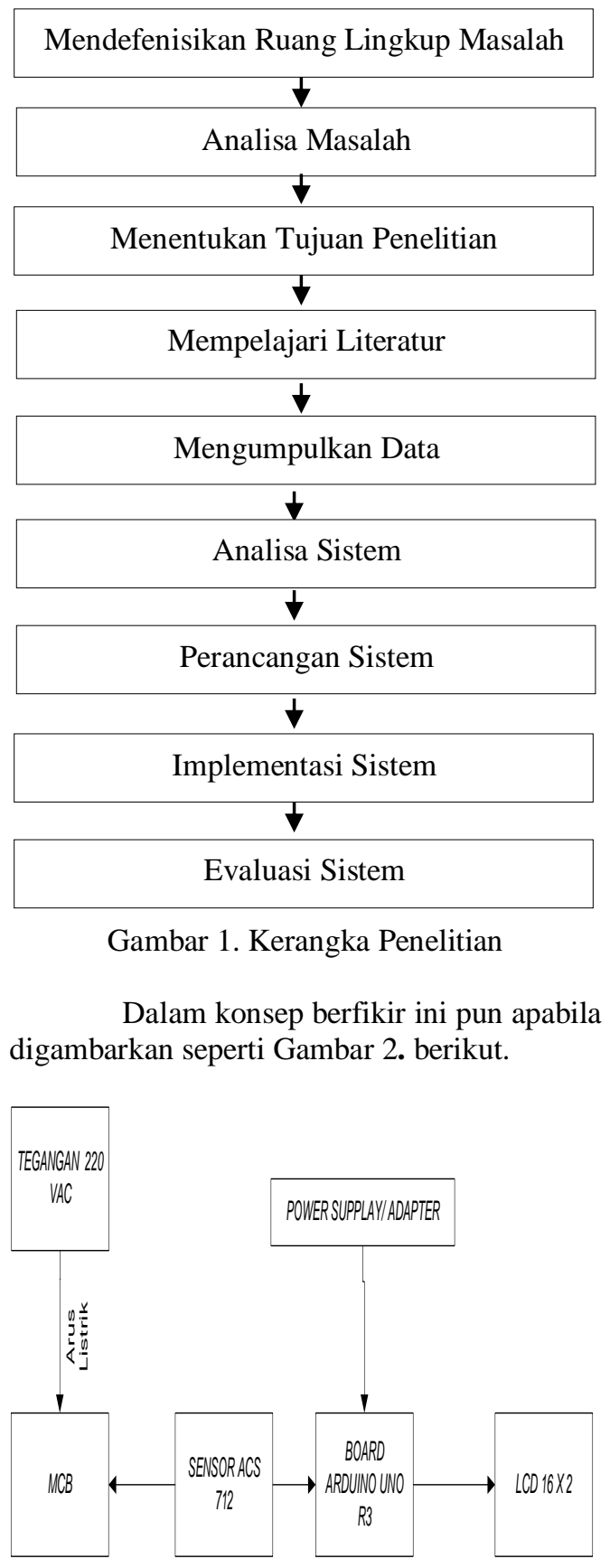

Gambar 2. Diagram kerangka pemikiran

Keterangan :

Tegangan 220 VAC mengalirkan arus listrik menuju ke MCB (Miniature Circuit Breaker), dan kemudian sensor arus Acs 712 
INF ORMA T I K A

Jurnal Informatika, Manajemen dan Komputer, Vol. 10 No. 1, Mei 2018

eISSN : 2580-3042

pISSN : 1979-0694

Membaca Arus yang masuk ke circuit Breaker. Kemudian sensor arus tersebut mengirimkan data yang diperolehnya ke Board Arduino Uno R3 dan memproses data tersebut kemudian Board Arduino Uno R3 tersebut menampilakan datanya $\operatorname{Ke} L C D 16 \times 2$.

\section{HASIL DAN PEMBAHASAN}

Prosedur sistem yang berjalan saat ini adalah ketika tegangan 220 Vac mengalirikan arus listrik menuju MCB (Miniature Circuit Breaker), yaitu dengan perantara mengunakan kabel tembaga dan dihubungakan dengan suatu beban seperti lampu,tv,dll. Kemudian untuk mengetahui berapa arus (A) pada $M C B$ (Miniature Circuit Breaker) tersebut. pada sistem yang berjalan saat ini masih mengunakan secara manual yaitu dengan mengunakan pengukur arus Ampermeter analog/digital.

Untuk lebih jelasnya sistem yang sedang berjalan pada saat ini, dan apabila di gambarkan seperti Gambar 3.

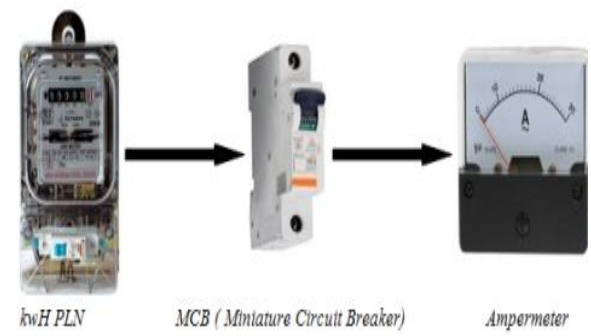

Gambar 3. Prosedur Sistem yang sedang berjalan

\subsection{Desain Alat}

Arus listrik dari meter kwh menuju $M C B$ ( Miniature Circuit Breaker) mengunakan perantara kabel alumunium atau tembaga. Kemudian sensor arus Acs 712 membaca arus listrik yang masuk ke $M C B$ Dan sensor arus tersebut mengirimkan data yang di peroleh ke mikrokontroller arduino uno untuk di proses. Selanjutnya berapa arus yang masuk ke $M C B$ tersebut di tampilkan dengan $L C D$ (liquid crystal display) 16x 2 karakter, untuk lebih jelas dapat di lihat pada Gambar 4 Dibawah ini.
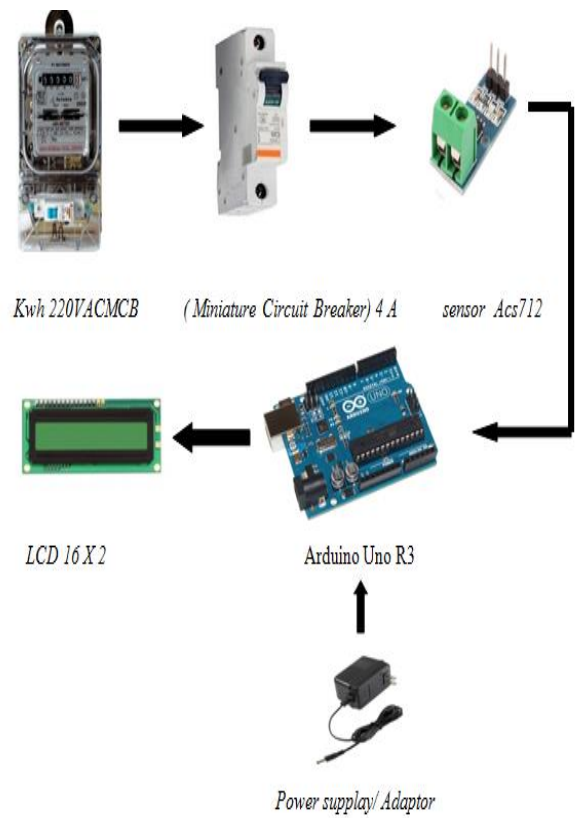

Gambar 4. Desain Alat

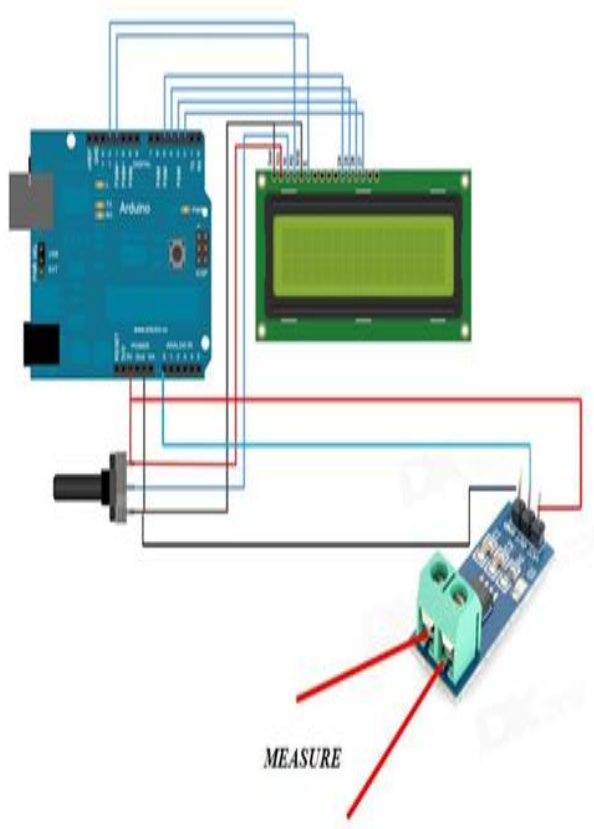

Gambar 5. Desain Rangkaian Monitoring 


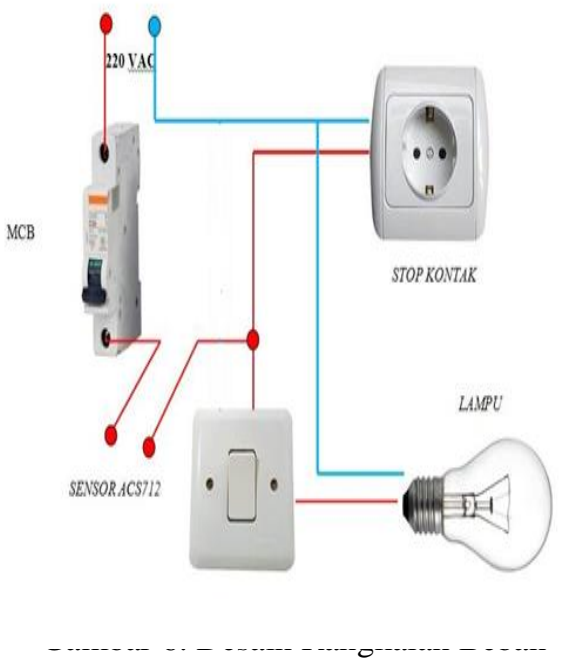

Pada Gambar 6 di atas beban (load) yang akan digunakan dalam penelitian ini berupa Lampu dan stop kontak untuk menghubungkan dengan alat yang lain.

\subsection{Flowchart}

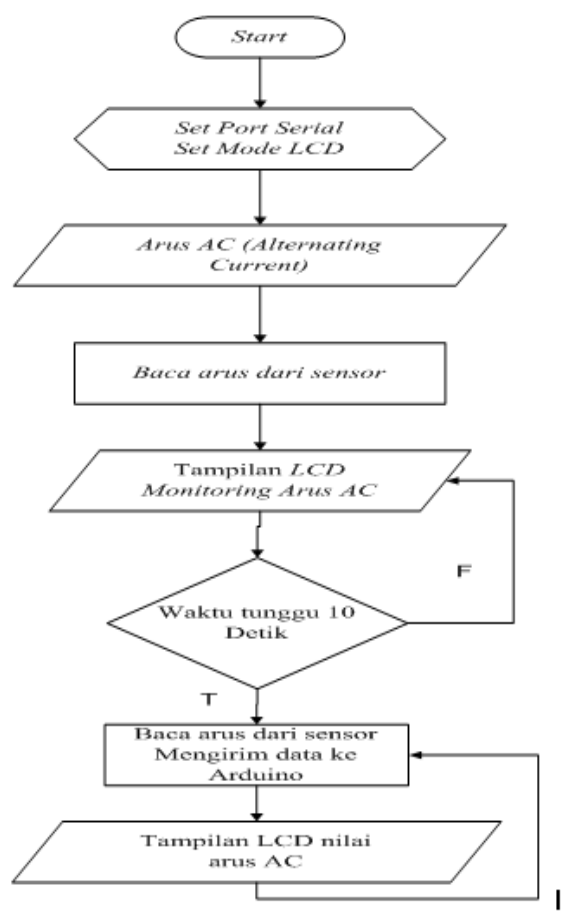

Gambar 7. Flowchart

\subsection{Tampilan Interface}

Tampilan interface yang akan dirancang menggunakan tampilan Liquid Crystal Display $(L C D)$ yang berukuran $16 x 2$ Karakter.

\section{LCD $16 \times 2$}

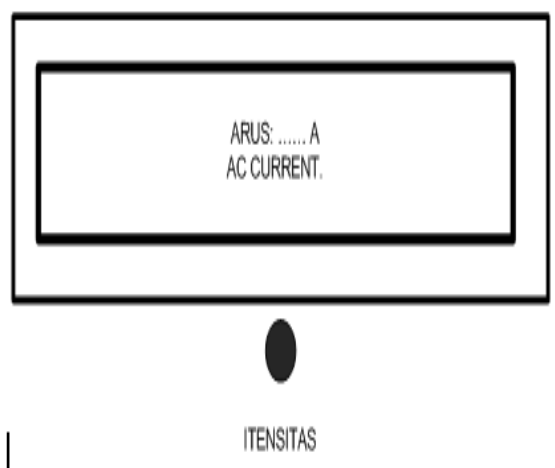

Gambar 8. Tampilan Interface

\subsection{Hasil Penelitian}

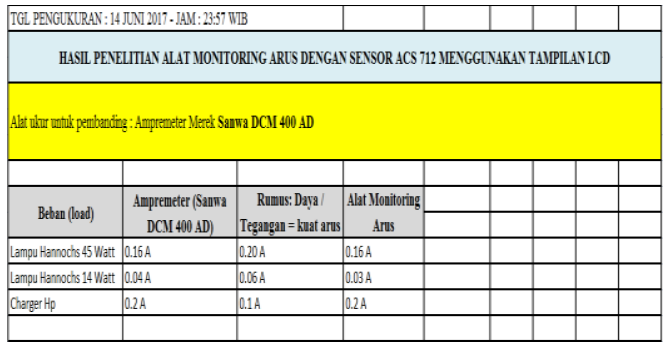

Gambar 9. Hasil Penelitian

\section{SIMPULAN}

Dengan melakukan perancangan dan pengujian sistem kerja alat monitoring arus pada circuit breaker dengan sensor ACS 712, maka dapat ditarik sebuah kesimpulan, yaitu :

1. Membantu teknisi dalam melakukan perbaikan.

2. Memberi kemudahan dalam melakukan penggukuran arus listrik.

3. Bisa memonitoring arus listrik secara langsung tanpa harus menggunakan alat ukur (Amper Meter).

4. Dengan mengunakan alat ini dapat meminimalisir kecelakan kerja bagi para teknisi. 
INF ORMA T I K A

Jurnal Informatika, Manajemen dan Komputer, Vol. 10 No. 1, Mei 2018

eISSN : 2580-3042

pISSN : 1979-0694

\section{REFERENSI}

Abdul Kadir. (2012). Buku Pintar C++ Untuk Pemula. MediaKom. Yogyakarta.

Andreas Alberth Mengko.(2016). E-Journal Teknik Elektro dan Komputer: Rancang Bangun Sistem Fleksible ATS (Automatic Transfer Switch) Berdasarkan Perubahan Arus Pada Instalasi Listrik Kapal Berbasis Microcontroller. ISSN: 2301-8402. 67-76.

Gentisya Tri Mardiani.(2013). Jurnal Ilmiah Komputer dan Informatika: Sistem Monitoring Data Aset Dan Inventaris PT. Telkom Cianjur Berbasi Web. ISSN : 2089-9033. 35-40.

Irwan Dinata, Wahri Sunanda.(2015). Jurnal Universitas Bangka Belitung: Implementasi Wireless Monitoring Energi Listrik Berbasis Web Database. ISSN: $2302-2949.83-$ 88.

Indrawoko Kurniadi, (2011). Logika Dan Algoritma Dasar Menggunakan Bahasa C++. Mitra Wacana Media. Jakarta.

Leoborus N. Hurlatu. (2016). E-Journal Teknik Elektro dan Komputer: Analisa Perancangan Sistem Scada Di Sistem Kelistrikan Minahasa. ISSN : 2301-8402. 37-42.

Mohammad Syahwill. (2013). Panduan Mudah Simulasi \& Praktek Mikrokontroler Arduino. Andi. Yogyakarta.

Mardalis, (2009). Metode Penelitian Suatu Pendekakatan Proposal, Bumi Aksara. Jakarta.

Prasetyo, Bambang. (2012). Metode Penelitian Kuantitatif. Rajawali Pers. Jakarta.

Pefrianus Bunga . (2015). E-Journal Teknik Elektro dan Komputer: Perancangan Sistem Pengendalian Beban Dari Jarak Jauh Menggunakan Smart Relay. ISSN: 230-8402. 65-75.

Syukriyadin.(2016). Jurnal Rekayasa Elektrika: Sistem Proteksi Arus Bocor Menggunakan Earth Leakage Circuit Breaker Berbasis
Arduino. ISSN: 1412-4785. 111118.

Yowono Marta Dinata, (2015). Arduino Itu Mudah, PT Alex Media Komputindo. Jakarta. 